\title{
Life Time Prevalence of Khat Chewing and Its Socio Demographic Correlates Among Adults Age 15-49 Years in Ethiopia: A Population Based Study Using the 2016 Demographic and Health Survey Data
}

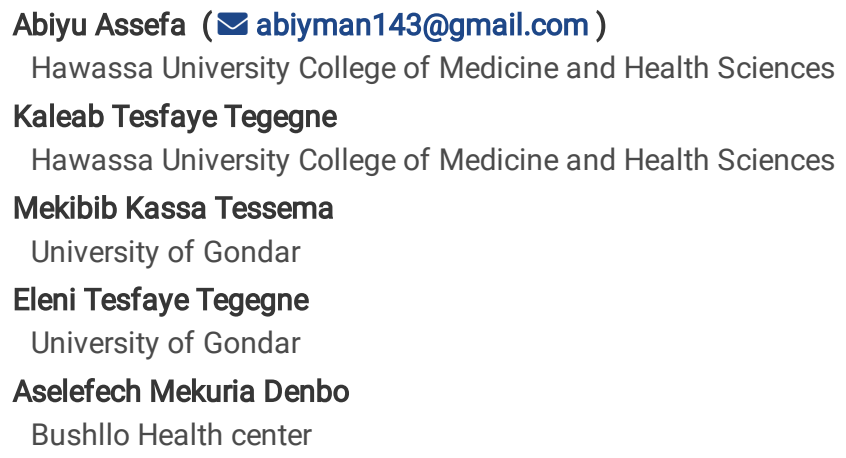




\section{Abstract}

Background: Khat chewing has been practiced from ancient by people in the Eastern part of Africa, the Arabian, Peninsula and other parts of the world. In Ethiopia, khat chewing is becoming habitual and the proportion of people chewing khat has significantly risen over the years and chewers' population in Ethiopia is now $16 \%$ from the country's population

The main aim of this study was to provide national data on life time prevalence of khat chewing and associated factors that will serve as evidence for policy and planning and as baseline data for further studies.

Methods: The data for this study was extracted from the 2016 EDHS. The 2016 EDHS is the fourth and most recent in the Demographic and Health Survey series in Ethiopia. Socio demographic variables were selected based on their availability in the dataset Our analysis included all men and women age 15-49 years which resulted in a total weighted sample of 27,289 Descriptive statistics were employed to show the distribution of sociodemographic characteristics Logistic regression model was used to determine the true association between chat chewing and basic sociodemographic factors

Results: Of the total sample of 27289 of men and women age $15-49$ years at the time of survey, $18.3 \%(n=5006)$ have life time khat chewing in Ethiopia,

About $71.7 \%$ of the variation in the outcome variable (khat chewing) is explained by the independent variables included in model

Men and women in the 15-19 age group 9.952 (AOR9.952 95\% $\mathrm{Cl} 6.156-16.091$ ) and Men and women age 15-49 years in urban areas 34.040 (AOR 34.040; 95\% Cl: 21.028-55.105) were found to be major contributing factors to the khat chewing

Conclusions Younger age and urban residence had a statistically significant association with khat chewing. Therefore, to effectively control khat chewing in Ethiopia, Creating awareness and increasing knowledge on the harmful effects of khat chewing are recommended. A particular attention should be given to young adolescent and urban areas

\section{Introduction}

Khat chewing has been practiced from ancient by people in the Eastern part of Africa, the Arabian, Peninsula and other parts of the world (1-4) In Ethiopia the proportion of people chewing khat has significantly risen over the years and chewers' population in Ethiopia is now $16 \%$ from the country's population (5)

In Ethiopia, khat has started to rapidly replace the precious cereal, coffee, fruits and other crops found in the highlands of Ethiopia. Farmers prefer khat due to different reasons including, it's profitability as a cash crop than others, less vulnerability to drought, and less labor power cost required for its cultivation.

However, khat producing farmers in Ethiopia start consuming khat and this culture is also continued expanding to the nearby secondary schools and urban dwellers (6)

The Magnitude of students' khat use in Ethiopia ranges from $13.4 \%$ to $41 \%$ for lifetime Youths' substance use contributes to the creation of a community with; substance use dependence, juvenile delinquencies, crimes, socio-economic and other public health problems. (7)

In Ethiopia, studies conducted among students of Jimma University showed that the current prevalence of khat chewing was $30.8 \%$ (8) Moreover, in Ethiopia, $42 \%$ of university instructors were lifetime khat chewers (9) Besides, other studies have also presented that the use of khat was significantly associated with age, gender and place of residence (10)

Similarly, a study in Gondar town revealed that the prevalence of khat chewing was high with statistically significant associations with sex, religion, and monthly income (11)

A 2011 report from the Ethiopian Demographic and Health (EDHS) survey showed khat chewing was more common in the Eastern, Central and Northeastern parts of the country; the highest wealth index quintile, older age group, unskilled workforce, rural residents, exposure to mass media and administrative regions were factors statistically associated with khat chewing practice (12)

Literature has revealed that a number of factors cause the increased khat consumption in different regions of Ethiopia. Among them are normalization in the community, social mobility to most khat chewing community, perceived non -side effect, affordability, type of occupation and availability of khat leaf in the whole year $(12,13)$.

To assist policy formation for coping with all forms of drug abuse in specific risk groups and the general population of Ethiopia, epidemiological studies are needed to identify risk groups and patterns of drug use behavior (14) 
The consumption of khat leaves is mostly practiced by adults in all regions and ethnic groups. Hence, most khat chewers are adults and exist in the active production stage, country labor force economic production, and chewers' livelihood situation remains questionable. This implies reducing number of chewers through identifying and reducing determinants is essential.

The main aim of this study was to provide national data on life time prevalence of khat chewing and socio demographic factors associated with it and the findings of this study will serve as evidence for policy and planning, and as baseline data for further studies.

\section{Methods}

\section{Data source, sampling and data collection}

The data for this study was extracted from the 2016 EDHS. The 2016 EDHS is the fourth and most recent in the Demographic and Health Survey series in Ethiopia [15]. The survey was conducted in nine regional states and two city administrations of Ethiopia [15]. Further details on sampling strategy can be found in the DHS manual [15].

A total of 16,583 eligible women and 11,606 eligible men between 15 and 49 years were approached to be interviewed. A response rate of $95 \%$ was observed with 15,683 women completing the interviews and response rate $86 \%$ among 11,606 men interviewed. The interviews included several standard questionnaires recording information ranging from basic socio-demographic information to detailed bio-medical information.

Our analysis included all men and women age 15-49 years which resulted in a total weighted sample of 27,289

\section{Outcome variable}

Life time prevalence of Khat chewing: The proportion of men and women age 15-49 years who had ever chewed Khat in their life time

According to EDHS all men and women age 15-49 years asked whether they ever chewed chat or not (1 if they ever chew chat, 0 otherwise).

\section{Co-variates}

The basic socio-demographic variables were selected based on their availability in the dataset The included basic socio-demographic factors are highest education level (categorized as "no education", "primary", "secondary ","more than secondary ")and working status in the past 12 months ("not working" or "working and occupation status ("not working", "non-agriculture" and "agriculture"), marital status ("never married", "currently married", "Living together", “Divorced/separated" and "Widowed”) age ("15-19 years", "20- 24 years", "25-29 years" 30-34 years" "35- 39 years" "40- 45 years" and "45- 49 years") and mothers exposure to mass media ("no" or "yes").

Number of living children (“1”, "1-2", “3-4" and " $5+$ ") , Literacy (“Cannot read at all ", "Can read part/whole sentence” and "Other")

Household factors included household wealth index (categorized as "poorest", "poorer", "middle", "richer" and "richest"),

The household wealth index was calculated using scores based on household assets with analyses conducted by the National Population Commission and Inner City Fund (ICF) International based on a methodology developed from previous DHSs [16, 17] and using methods recommended by the World Bank Poverty Network and United Nations International Children's Emergency Fund (UNICEF) [18].

Community level factors recorded were the place of residence ("rural" or "urban") and geographical region.

The geographical regions were grouped into nine regional states of Ethiopia; namely Afar, Amhara, Benishangul-Gumuz, Gambella, Harari, Oromia, Somali, Southern Nations Nationalities and Peoples' Region (SNNP), and Tigray, and two city administrations named Addis Ababa and Dire Dawa [15].

Statistical analysis

Sampling weights provided with the EDHS dataset were used during analysis. Further details on sample weights can be found in the EDHS report [15].

Descriptive statistics were employed to show the distribution of background characteristics. We used logistic regression model to determine the true association between chat chewing and basic socio-demographic factors .Both unadjusted and adjusted odds $\backslash$ ratios (ORs) were reported with $95 \%$ confidence intervals $(95 \% \mathrm{Cl}$ ). Besides, diagnostic tests were done, particularly goodness of fit of the model by the Hosmer and Lemeshow test; (where p-value of 0.875 was found), The Cronbach's alpha result of the variables is 0.900 The Nagelkerke $\mathrm{R}$ Square shows that about $71.7 \%$ of the variation in the outcome variable (chat chewing) is explained by this logistic model The overall accuracy of this model to predict subjects who ever chew chat (with a predicted probability of 0.5 or greater) is $89.4 \%$ All analyses were performed using statistical software SPSS (Version 16.0 ).

Ethics approval

Page 3/11 
This study is a secondary analysis of publicly available dataset where permission was obtained through registering with the DHS website and therefore no ethics approval was required.

\section{Result}

\section{Baseline characteristics}

Of the total sample of 27289 of men and women $15-49$ years at the time of survey, $18.3 \%(n=5006)$ had life time prevalence of khat chewing (Table 3).

As summarized in Table 1, majority (57.5\%) of the respondents were female and a predominant percentage of the men and women $15-49$ years lived in rural areas (78.8\%), respondents in the regions of Oromia were (37.1\%) and Amhara (24.3\%). $32.1 \%$ of men and women $15-49$ years reported not working in the past 12 months at the time of survey, and $39.2 \%$ did not have any formal education. In addition to education status, around $45.9 \%$ of men and women $15-49$ years reported having poor literacy skills and could not read at all

Majorities (39.8\%) of the respondent's occupation were agriculture, $28.1 \%$ were non agriculture employee in addition, and $43.8 \%$ of the respondents were orthodox religion followers

In terms of men and women 15- 49 years age, overall $21.8 \%$ of men and women were between 15 and 19 years of age

Most men and women 15- 49 years (58.9\%) reported as currently married at the time of the survey. Of the total, only $16.4 \%$ were in lowest wealth quintile and $26.0 \%$ were in the highest wealth quintile

In terms of the number of living children , about $39.7 \%$ of men and women 15 - 49 years reported to have one living children and $20.7 \%$ had more than 5 number of living children during survey .

Regarding exposure to mass media, $6.2 \%$ read newsletter, $18.1 \%$ watch to TV and $21.7 \%$ listen to radio

\section{Bi-variable analysis}

An increase in one-year in age $(\mathrm{COR}=0.174 ; 95 \% \mathrm{Cl}: 0.165-0.183)$ were less likely to chew chat

Odds of chat chewing among men and women age 15-49 years in urban areas were 9.709 (COR19.709; 95\% Cl: 18.303-21.223) times higher than rural areas

Men and women age 15-49 years in afar are 0.799 (COR 0.799; 95\% Cl: 0 719- 0.888 ) times less likely to chew chat than tigray region of Ethiopia Men and women age 15-49 years in Amhara are 0.002 (COR $0.002 ; 95 \% \mathrm{Cl}$ : 0.002-0.003) times less likely to chew chat than tigray region of Ethiopia

Men and women age 15-49 years in poorest category are 0649 (COR 0 649; 95\% Cl: 0.598- 0.704 ) less likely to chew chat than poorer categories Men and women age 15-49 years who were never married 0.078 (COR $0.078 ; 95 \% \mathrm{Cl}$ : 0.072-0-084) less likely to chew chat than married

\section{Multivariable analysis}

residence they live had significant association with men and women 15-49 years living in urban areas were 34.040 times higher odds of chat chewing (AOR 34.040; 95\% Cl: 21.028-55.105) compared to men and women 15-49 years who had live in rural areas

Demographically, since age is a quantitative numerical variable, an increase in one-year in age has 9.952 (AOR9.952 95\% Cl 6.156- 16.091) times decrease in odds of chat chewing

Table 2 shows unadjusted and adjusted odds ratios (AOR) that were calculated to determine the strength of association between the co-variates and life time prevalence of chat chewing

\section{Discussion}

\section{Life Time Prevalence of Khat Chewing}

Of the total sample of 27289 of men and women $15-49$ years at the time of survey, $18.3 \%(n=5006)$ have life time prevalence of chat chewing which is comparable to previous studies $13.4 \%$ to $41 \%, 17.5 \%, 17.9 \%, 18.3 \%$ respectively $[7,9,19,20]$ and higher compared to $15.3 \%, 16 \%, 15.36 \%$, $14 \%$ 7.5\%, 15.8\%, 15.3\%, 9.6\% respectively [12,21-27].and lower compared to 46\%., $23.0 \%, 19 \%, 19.9 \%, 48.6 \%$., $50 \%, 30.6 \%, 19.6 \%, 24.7 \%$, $74.55 \%$, $22.3 \%, 23.61 \%, 29.6 \%, 27.14 \%, 37.1 \%, 65.6 \%$ respectively $(8,24,25,28,29,30-34,36-41)$ and Study by(35) is also higher compared to this finding 
Furthermore, the possible explanations for the observed differences in khat chewing could be due to differences in sample characteristics, in the definitions used by studies. In our study life time prevalence of Khat use was measured by asking whether they ever chew chat in their previous life and others used define Khat use as "using of Khat for the previous one year or one month" and methodological differences.

\section{Socio demographic factors associated with life time prevalence of khat chewing}

In our study the life time prevalence of khat chewing was not statistically significantly higher in males compared with females similar to findings from 2015 national Non-communicable diseases STEPS survey (25).

According to our findings life time prevalence of khat chewing in the general population of Ethiopia was $26.7 \%$ among men and $12.1 \%$ among women of 15-49 years which is similar with EDHS 2011 27.3\% among men and 11.0\% among women of 15-49 years [26.].

In our study age and area of residence significantly associated with khat chewing contrarily with study in Southwestern Saudi Arabia (41)

In this study an increase in one-year in age has 9.952 (AOR9.952 95\% Cl 6.156-16.091) times decrease in odds of chat chewing which is similar to previous studies (8-9, 21, 27,38,41-43).

This study is contrarily with previous studies $[12,48,21,39)$

Many factors increase the risk of khat chewing during adolescence, including socioeconomic status, neighborhood, cultural context, peer influence, teachers' influence and perhaps most importantly, family influences (44).

It is reported that social acceptability of khat chewing and socialization of this habit increase the likelihood of adolescents adopting the behaviour in Jazan Region (45). For Yemenis, khat may be less of a drug than a medium for socialization (4).

This fall in the age of initiation of khat chewing indicates the failure of prevention strategies (46).

Teenagers who want to try new things and can be convinced by their friends and may try to chew khat for the purpose of relaxation (28).

This indicates that the more educated groups who represent the most productive sections of the society are affected by the khat chewing habit (8). This showed that the above ages are in the age group called teenage in which those who are in this period want to try everything by themselves and can be exposed to different kinds of substances $(9,43)$. The most frequent reasons for continuing chewing khat were promoting dialogue and social discussion, making the chewer feel refreshed, more energetic, alert and attentive(41).

Similar claims of positive physiological aspects to khat chewing and strong energizing effect of workers have been reported elsewhere (47).

It implies older individuals may be deciding to wait for not chewing in order to deal with their family cases unlike younger that may be sensitive to do what they observe in their life and khat chew.

In this study residence had significant association with men and women 15-49 years living in urban areas were 34.04 times higher odds of chat chewing (AOR 34.040; 95\% Cl: 21.028-55.105) compared to men and women 15-49 years who had live in rural areas which is similar to previous studies $(25,32,42,49)$ and contrarily to studies $(12,33)$.

In this study Higher prevalence in urban observed because from no educated respondents (10701) majority of 54.0\% (5779) respondents in urban residence have no education.

According to previous study education is a protective factor for current khat chewing. Participants who are in the no education group are more likely to chew khat than those who are educated (25) Lower educational status was found to be a significant independent predictor of current khat chewing (37).

The study conducted from the Jazan region, Saudi Arabia, which showed that illiterates were at higher odds of chewing khat [50].

The reason could be uneducated men would have a lack of information on the negative consequences of khat on their health [51].

In our study age and residence significantly associated with life time prevalence of khat chewing and this is similar with the previous study that reported khat chewing was associated with age and residence [52].

\section{Limitations Of The Study}

The cross sectional nature of the study design might not show the cause and effect relationships between the explanatory variables and Khat use. Furthermore, Khat use has a social taboo, in which participants might under report their experience and this may introduce social desirability bias. 


\section{Conclusion}

Younger age (15-19) and urban residence had a statistically significant association with life time prevalence of khat chewing.

Therefore, to effectively control khat chewing in Ethiopia, Creating awareness and increasing knowledge on the harmful effects of khat chewing are recommended. A particular attention should be given to young adolescent and urban areas.

\section{Abbreviations}

AOR: Adjusted odds ratio; Cl: Confidence interval; COR: crude odd ratio; DHS: Demographic health survey; EDHS: Ethiopian demographic and health survey; ICF: Inner city fund; UNICEF: United Nations International Children's Emergency Fund

\section{Declarations}

\section{Ethics approval and consent to participate}

This study is a secondary data analysis of the EDHS, which is publicly available, approval was sought from MEASURE DHS/ICF International and permission was granted for this use. The original DHS data were collected in conformity with international and national ethical guidelines. Ethical clearance was provided by the Ethiopian Public Health Institute (EPHI) (formerly the Ethiopian Health and Nutrition Research Institute (EHNRI)

Review Board, the National Research Ethics Review Committee (NRERC) at the Ministry of Science and Technology, the Institutional Review Board of ICF International, and the United States Centers for Disease Control and Prevention (CDC). Written consent was obtained from respondents and data were recorded anonymously at the time of data collection during the EDHS 2016.

\section{Consent for publication}

Not applicable.

\section{Availability of data and materials}

The survey datasets used in this study was based on publicly available dataset that is freely available online with no participant's identity from http://www.dhsprogram.com/data/available-datasets.cfm. Approval was sought from MEASURE DHS/ICF International and permission was granted for this use.

\section{Competing interests}

The authors declare that they have no competing interests.

\section{Funding}

This study did not receive any funding from any organization

\section{Authors' contributions}

KTT, ETT, AAA and MKT were involved in formatting the research question. KTT performed the analysis with assistance from ETT, AAA and MKT. All authors prepared the initial draft of the manuscript. ETT, AAA, AMD and KTT critically revised the manuscript for intellectual content. All authors approved the final version of the manuscript.

\section{Acknowledgements}

We are grateful to Measure DHS, ICF International Rockville, Maryland, USA for providing the 2016 EDHS data for this analysis.

\section{Author details}

1Hawassa college of Health Science, Department of Public Health, Hawassa , Ethiopia

2 Leishmania Research and Treatment Center University of Gondar Gondar, Ethiopia

3 University of Gondar, College of Medicine and Health Sciences, School of Nursing, Gondar, Ethiopia.

4 Bushllo Health Center Hawassa Ethiopia

\section{References}


1. Al-Hebshi N, Skaug N: Khat (Catha edulis)-an updated review. Addiction biology 2005, 10(4):299-307.

2. Stevenson M, Fitzgerald J, Banwell C: Chewing as a social act: cultural displacement and khat consumption in the East African communities of Melbourne. Drug and Alcohol Review 1996, 15(1):73-82.

3. Fasanmade A, Kwok E, Newman L: Oral squamous cell carcinoma associated with khat chewing. Oral Surgery, Oral Medicine, Oral Pathology, Oral Radiology, and Endodontology 2007, 104(1):e53-e55.

4. Luqman W, Danowski T: The use of khat (Catha edulis) in Yemen: social and medical observations. Annals of internal medicine 1976, 85(2):246-249.

5. Gebrie A, Alebel A, Zegeye A, Tesfaye B (2018). Prevalence and predictor sof khat chewing among Ethiopian university students: systematic review and meta-analysis.13:4.https://doi.org/10.1371/journal.pone.0195718.

6. Feyisa TH, Aune JB. Khat Expansion in the Ethiopian Highlands: Effects on the Farming System in Habro District. Mountain Research and Development. May 2003;23(2):5 PubMed.

7. Astatkie A, Demissie M, Berhane Y, Worku A. Prevalence Of and factors associated with regular khat chewing among university students in Ethiopia. Subst Abuse Rehabil. 2015;6:41-50.

8. Gelaw Y, Haile-amlak A.Khat chewing and its socio-demographic correlates among the staff of Jimma University. Ethiop. J. Heal. Dev. 2004; 18(3):179-184.

9. Kebede Y.Cigarette Smoking and Khat chewing among college students in North West Ethiopia. Ethiop. J. Heal. Dev. 2002; 16(1):9-17.

10. Ageely HM. Prevalence of Khat chewing in college and secondary (high) school students of Jazan region, Saudi Arabia. Harm Reduct. J.2009;7:5-11.

11. Teni F, Surur A, Hailemariam A, Aye A, Mitiku G, Gurmu A et al. Prevalence, Reasons, and Perceived Effects of Khat Chewing Among Students of a College in Gondar Town, Northwestern Ethiopia: A Cross-Sectional Study. Ann. Med. Health Sci. Res. 2015; 5(6): 454-460.

12. Haile D, Lakew Y. Khat Chewing Practice andAssociated Factors among Adults in Ethiopia: Further Analysis Using the 2011 Demographic andHealth Survey. PLoS One. 2015; 10(6):1-11.

13. Megerssa B, Esayas A, Mohamed A (2014). Socio-Economic Impact of Khat in Mana District, Jimma Zone, South Western Ethiopia. Discourse Journal of Agriculture and Food Sciences 2(2):21-32.

14. Seyoum G, et al. Rapid assessment of the situation of drug and substance abuse in selected urban areas in Ethiopia, Addis Ababa, AAU, Nov. 1195: 9-55..

15. Central Statistical Agency (CSA) [Ethiopia] and ICF. 2016 Ethiopia Demographic and Health Survey Key Findings. 2017. https://dhsprogram. com/pubs/pdf/SR241/SR241.pdf Accessed 18 June 2018.

16. Central Statistical Authority/Ethiopia and ORC Macro. Ethiopia Demographic and Health Survey 2000. Addis Ababa, Ethiopia; 2001. https://www. dhsprogram.com/pubs/pdf/FR118/FR118.pdf. Accessed 11 July 2018.

17. Central Statistical Authority/Ethiopia and ORC Macro. Ethiopia Demographic and Health Survey 2005. Addis Ababa, Ethiopia; 2006. https://www.dhsprogram.com/ pubs/pdf/fr179/fr179\%5B23june2011\%5D.pdf. Accessed 21 June 2018.

18. Filmer D, Pritchett L. Estimating wealth effects without expenditure data or tears: an application to educational enrollments in states of India. Demography. 2001;38(1):115-32.

19. Dachew BA, Bifftu BB Tiruneh BT (2015) Khat use and Its Determinants among University students in Northwest Ethiopia. Int J Med Sci Public Health 4: 319323

20. Mekasha A. Clinical aspects of khat (Catha edulis forsk): In: Proceedings of the International Symposium on khat 1983; 77-83.

21. Emishaw Dires, Matiwos Soboka , Habtamu Kerebih and Garumma Tolu Feyissa Dires et al Factors Associated with Khat Chewing among High School Students in Jimma Town Southwest Ethiopia., J Psychiatry 2016, 19:4 DOI: 10.4172/2378-5756.1000372

22. Lakew A, Tariku B, Deyessa N, Reta Y (2014) Prevalence of Catha edulis ( Khat ) Chewing and Its Associated Factors among Ataye Secondary School Students in Northern Shoa Ethiopia. Advances in Applied Sociol 4: 225-233

23. Alemayehu G (2005) Assessment of prevalence, determinants and effects of mental distress among Alemaya university students. Doctoral dissertation

24. Kebede,A.Alem,G.Mitikeetal.,"Khatandalcoholuseand risky sex behavior among in-school and out-of-school youth in Ethiopia,” BMC Public Health,vol.5,articleno.109,2005

25. Teklie H, Gonfa G, Getachew T Prevalence of Khat chewing and associated factors in Ethiopia: Findings from the 2015 national Non communicable diseases STEPS survey Ethiop. J. Health Dev. 2017;31(Special Issue)

26. CSA and ICF International. Ethiopia Demographic and Health Survey. Addis Ababa, Ethiopia and Calverton, Maryland, USA, 2012

27. Aklilu S, Anteneh M Hiwot K (2014) Prevalence and Associated Factors of Khat Chewing Among Atse Fasil Campus Students, University of Gondar, North West Ethiopia. J Psychol Clin Psychiatry 1: 1-8. 
28. Assessment of khat chewing among preparatory school students in Addis Ababa athesis submitted to the school of public health, university of gondar, in partial fulfillment of the requirements for the degree of master's in public healthj june, 2011(unpublished)

29. Wondemagegn A, Cheme, M , and Kibret K Perceived Psychological, Economic, and Social Impact of Khat Chewing among Adolescents and Adults in Nekemte Town, East Welega Zone, West Ethiopia BioMed Research InternationalVolume 2017, Article ID 7427892, 9 pages https://doi.org/10.1155/2017/7427892

30. Alem, D. Kebede, and G. Kullgren, "The prevalence and socio-demographic correlates of khat chewing in Butajira, Ethiopia," Acta Psychiatrica Scandinavica,vol.100,no.S397,pp. 84-91, 1999

31. A. M. Ayanna, H. T. Sherief, and D. B. Teklay, "Effect of khat chewing on blood pressure and heart rate community based study," The Ethiopian Journal of Health Development,vol.16,no. 3, pp. 326-334, 2002

32. Y. Mulugeta, "Khat chewing and its associated factor among college students in Bahir Dar Town, Ethiopia," Science Journal of Public Health,vol.1,no.5,pp.209-214,2013

33. Belayneh Z Mekuriaw B Prevalence and associated factors of Khat chewing among people with HIV/AIDS at rural health centers of Ethiopia: a cross-sectional study (unpublished)

34. Addis Y, Adamu C, Abate D and Mossie H Determinants of khat chewing among urban households of Wolkite Town, Gurage Zone, Ethiopia Journal of Development and Agricultural Economics Vol. 11(3), pp. 63-70, March 2019)

35. Awell Y, Yerra R, Tadele E, Getu K, Dagim A, Hailekiros G, Tesfamichael G, Yasodha K (2016). Socio-Economic and Health Effects of Khat Chewing in Mekelle, Tigray Region, Ethiopia 8(1):1122

36. Mossie A. The prevalence and socio-demographic,characteristics of khat chewing in Jimma town, Southwest Ethiopia. Ethiop. J Health Sci. 2002: 12(2): 69-80

37. Akalu T, Baraki A, Wolde H, Lakew A and Gonete K Factors affecting current khat chewing among male adults 15-59 years in Ethiopia, 2016: a multi-level analysis from Ethiopian Demographic Health Survey BMC Psychiatry (2020) 20:21

38. AL-abed, A et ale Family Context and Khat Chewing among Adult Yemeni Women: A Cross-Sectional Study BioMed Research International Volume 2014, Article ID 505474, 6 pages http://dx.doi.org/10.1155/2014/505474

39. Tessema Z and Zeleke T Spatial Distribution and Factors Associated with Khat Chewing among Adult Males 15-59 Years in Ethiopia Using a Secondary Analysis of Ethiopian Demographic and Health Survey 2016: Spatial and Multilevel Analysis psychiatry Journal Volume 2020, Article ID 8369693, 12 pages https://doi.org/10.1155/2020/8369693

40. Azale T. Prevalence and risk factors of khat chewing among in school and out of school youth in North Western Ethiopia , Gondar town. 2007

41. Nabil J. Awadalla and Hassan A. Suwaydi Prevalence, determinants and impacts of khat chewing among professional drivers in Southwestern Saudi Arabia Eastern Mediterranean Health Journal EMHJ • Vol. 23 No. $3 \cdot 2017$

42. Zeleke,W.Awoke,E.Gebeyehu,and F.Ambaw," Khat chewing practice and its perceived health effects among communities of Dera Woreda, Amhara region, Ethiopia," Open Journal of Epidemiology, vol. 3, pp. 160-168, 2013

43. Fekade A. Challi J. Tadesse M. Khat chewing among Agaro secondary school students. Ethiop Med J. 1994; 32: $161-166$

44. Johnson V, Pandina RJ. Effects of the family environment on adolescent substance use, delinquency, and coping styles. Am J Drug Alcohol Abuse. 1991;17(1):71-88. PMID:2038985

45. Mahfouz MS, Alsanosy RM, Gaffar AM. The role of family background on adolescent khat chewing behavior in Jazan Region. Ann Gen Psychiatry. 2013 May;12(1):16. PMID:23688046

46. Alsanusy R, El-Setouhy M. Why would khat chewers quit? An in-depth, qualitative study on Saudi khat quitters. Subst Abus. 2013;34(4):38995. PMID:24159910

47. Ageely HM. Health and socioeconomic hazards associated with khat consumption. J Family Community Med. 2008 Jan;15(1):1-9. PMID:23012161

48. Reda AA, et al. Prevalence and determinants of khat (Catha edulis) chewing among high school students in eastern Ethiopia: a cross-sectional study. PLoS One. 2012;7(3):e33946

49. Mekuriaw B , Belayneh Z and Yimenu Y Magnitude of Khat use and associated factors among women attending antenatal care in Gedeo zone health centers, southern Ethiopia: a facility based cross sectional study

50. Alsanosy RM, Mahfouz MS, Gaffar AM. Khat chewing habit among school students of Jazan region, Saudi Arabia. Plos one. 2013;8(6):e65504

51. Aden A, et al. Socio-economic effects of khat chewing in north eastern Kenya. East Afr Med J. 2006;83(3):69-73

52. W. A.Milaat,M.A.Salih,I.A.Bani,and H.M.Ageely,Jazan Need Assessment Health Survey, Faculty of Medicine, Jazan King Abdulaziz University, Jeddah, Saudi Arabia, 2005

\section{Tables}

Table1. Individual, household and community level characteristics of men and women 15-49 years, Ethiopia 2016. 


\begin{tabular}{|c|c|}
\hline Socio-demographic factors & $N(\%)$ \\
\hline & SEX \\
\hline Male & $11606(42.5 \%)$ \\
\hline \multirow[t]{2}{*}{ Female } & $15683(57.5 \%)$ \\
\hline & Wealth index \\
\hline Lowest & $4472(16.4 \%)$ \\
\hline Second & $4927(18.1 \%)$ \\
\hline Middle & $5224(19.1 \%)$ \\
\hline Fourth & $5566(20.4 \%)$ \\
\hline \multirow[t]{2}{*}{ Highest } & $7098(26.0 \%)$ \\
\hline & Residence \\
\hline Urban & $5779(21.2 \%)$ \\
\hline \multirow[t]{2}{*}{ Rural } & $21509(78.8 \%)$ \\
\hline & Age category \\
\hline $15-19$ & $5953(21.8 \%)$ \\
\hline $20-24$ & $4645(17.0 \%)$ \\
\hline $25-29$ & $4934(18.1 \%)$ \\
\hline $30-34$ & $3980(14.6 \%)$ \\
\hline $35-39$ & $3318(12.2 \%)$ \\
\hline $40-44$ & 2496(9.1\%) \\
\hline \multirow[t]{2}{*}{$45-49$} & $1961(7.2 \%)$ \\
\hline & Religion \\
\hline \multirow[t]{2}{*}{ Orthodox } & $11946(43.8 \%)$ \\
\hline & working status (past 12 months) \\
\hline \multirow[t]{2}{*}{ Working } & $18518(67.9 \%)$ \\
\hline & Marital status \\
\hline \multirow[t]{2}{*}{ Married } & $16059(58.9 \%)$ \\
\hline & Literacy \\
\hline \multirow[t]{2}{*}{ Cannot read at all } & $12530(45.9 \%)$ \\
\hline & Number of living children \\
\hline 0 & $10843(39.7 \%)$ \\
\hline $1-2$ & $5972(21.9 \%)$ \\
\hline $3-4$ & $4834(17.7 \%)$ \\
\hline \multirow[t]{2}{*}{$>5$} & $5640(20.7$ \\
\hline & Frequency of reading newspaper \\
\hline yes & $1703(6.2 \%)$ \\
\hline \multirow[t]{2}{*}{ no } & $25586(93.8 \%)$ \\
\hline & Frequency of listening to the radio \\
\hline yes & $5919(21.7 \%)$ \\
\hline \multirow[t]{2}{*}{ no } & $21370(78.3 \%)$ \\
\hline & Frequency of watching TV \\
\hline
\end{tabular}

Page 9/11 


\begin{tabular}{|ll|}
\hline yes & $4938(18.1 \%)$ \\
\hline no & $22351(81.9 \%)$ \\
\hline Tigray & Region \\
\hline Afar & $1837(6.7 \%)$ \\
\hline Amhara & $210(0.8 \%)$ \\
\hline Oromiya & $6628(24.3 \%)$ \\
\hline Somali & $10110(37.1 \%)$ \\
\hline Benishangul-Gumuz & $760(2.8 \%)$ \\
\hline SNNPR & $278(1.0 \%)$ \\
\hline Gambela & $5659(20.7 \%)$ \\
\hline Harari & $79(0.3 \%)$ \\
\hline Addis Ababa & $67(0.2 \%)$ \\
\hline Dire Dawa & $1503(5.5 \%)$ \\
\hline Not & $156(0.6 \%)$ \\
\hline Non-agriculture & $1887(6.9 \%)$ \\
\hline Noccupation
\end{tabular}

Table 2 Unadjusted and adjusted Odds Ratio for life time prevalence of khat chewing in Ethiopia 2016. 


\begin{tabular}{|c|c|c|c|c|}
\hline \multirow[t]{2}{*}{ Variable } & \multicolumn{2}{|l|}{ Unadjusted } & \multicolumn{2}{|l|}{ Adjusted } \\
\hline & OR & P-value & OR & P-value \\
\hline Age & $0.174,(0.165,0.183)$ & 0.000 & $9.952,(6.156,16.091)$ & 0.000 \\
\hline \multicolumn{5}{|l|}{ Residence } \\
\hline Urban & $19.709(18.303,21.22)$ & 0.000 & $34.040,(21.028,55.105)$ & 0.000 \\
\hline Rural & 1.00 & & & \\
\hline \multicolumn{5}{|l|}{ Region } \\
\hline Tigray & $0.979,(0.730,1.312)$ & 0.886 & not Retained in model & \\
\hline Afar & $0.799,(0.719,0.888)$ & 0.000 & not Retained in model & \\
\hline Amhara & $0.002 .(0.002,0.003)$ & 0.000 & not Retained in model & \\
\hline \multicolumn{5}{|l|}{ Wealth quintile } \\
\hline Lowest & $0 \quad 649,(0.598,0.704)$ & 0.000 & not Retained in model & \\
\hline Second & 1.00 & & & \\
\hline \multicolumn{5}{|l|}{ Marital status } \\
\hline Never married & $0.078,(0.072,0-084)$ & 0.000 & not Retained in model & \\
\hline Married & 1.00 & & & \\
\hline
\end{tabular}

Backward stepwise model with dichotomous outcome of $(0=$ no life time prevalence of chat chewing, $1=$ life time prevalence of chat chewing)

Table 3 socio demographic characteristics of men and women age 15-49 years according to life time prevalence of khat chewing in Ethiopia 2016.

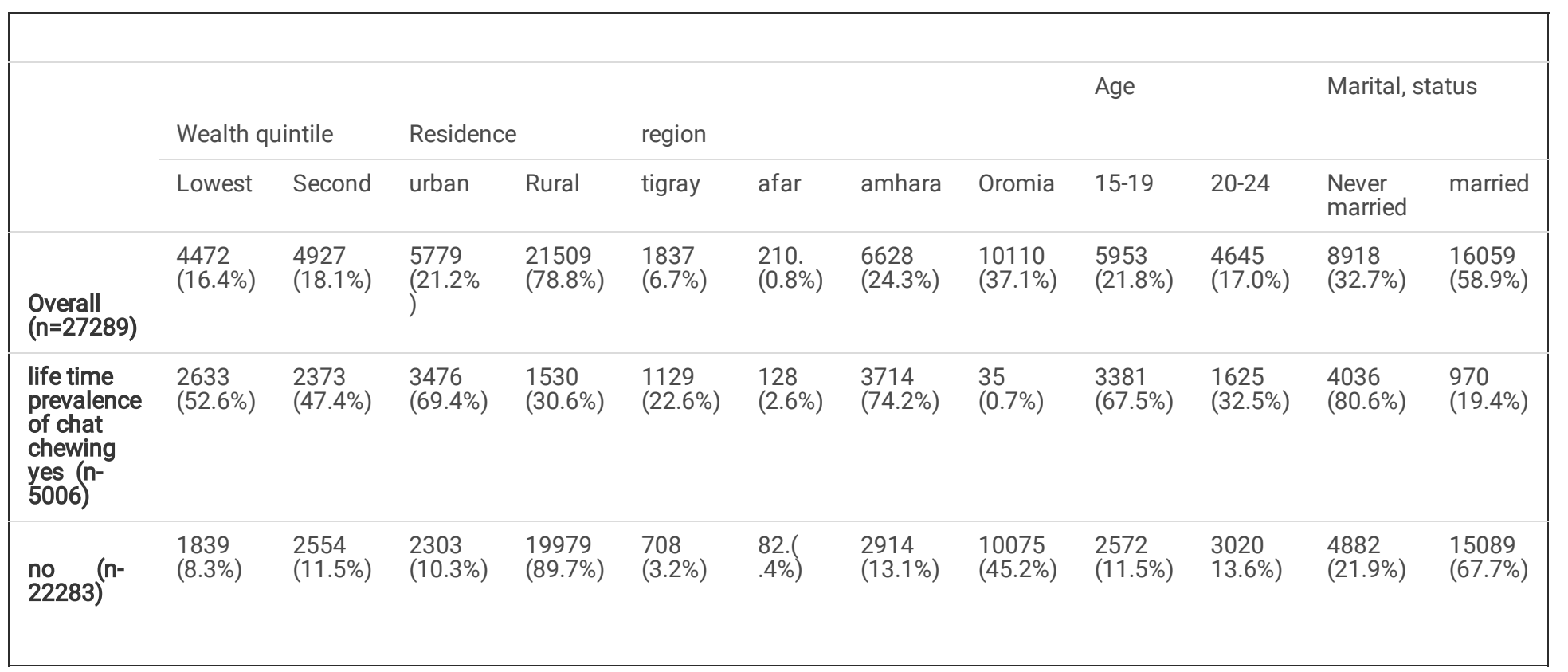

